\title{
Glycerol Acetylation with Propionic Acid Using Iron and Cobalt Oxides in Al-MCM-41 Catalysts
}

\author{
Fábio R. Tentor ${ }^{1}$, Diego B. Dias ${ }^{1}$, Mateus R. Gomes ${ }^{1}$, João Guilherme P. Vicente ${ }^{2}$, \\ Lúcio Cardozo-Filho ${ }^{3}$, Márcio E. Berezuk ${ }^{1, *}$ \\ ${ }^{1}$ Department of Chemical Engineering, Federal University of Technology - Paraná, Apucarana \\ 86812460, Paraná, Brazil. \\ ${ }_{2}^{2}$ FACENS University Center, Sorocaba 18085784, São Paulo, Brazil. \\ ${ }^{3}$ Department of Chemical Engineering, State University of Maringá, Maringá 87020900, Paraná, \\ Brazil.
}

Received: 24th September 2020; Revised: $6^{\text {th }}$ October 2020; Accepted: $5^{\text {th }}$ November 2020; Available online: $9^{\text {th }}$ November 2020; Published regularly: December 2020

\begin{abstract}
In this work, Al-MCM-41 molecular sieves were synthesized, containing iron and/or cobalt oxides, impregnated by incipient wetness method, characterized and applied as catalysts in the acetylation reaction of glycerol with propionic acid to produce green glyceryl propionate molecules of high commercial value. According to this, X-ray Diffraction (XRD), X-ray Fluorescence (XRF), Fourier Transform Infra Red (FT-IR), adsorption/desorption $\mathrm{N}_{2}$ isotherms, textural analysis, and Scanning Electron Microscope (SEM) analysis were recorded to evaluate the main characteristics of materials. The presence of Lewis and Brønsted acidic sites and catalysts surface area were observed as important key points to functionalize acetylation reaction. Thus, time reaction, temperature, and glycerol / propionic acid ratio varied to improve the most suitable reaction conditions and behaviors. As a result, glycerol conversion was above $96 \%$, followed by $68 \%$ of selectivity to glyceryl monopropionate as well as the formation of glyceryl di- and tri- propionate and a small amount of ethylene glycol dipropionate as an undesired product. Copyright (C) 2020 BCREC Group. All rights reserved
\end{abstract}

Keywords: Glycerol; propionic acid; acetylation; Al-MCM-41; iron; cobalt

How to Cite: Tentor, F.R., Dias, D.B., Gomes, M.R., Vicente, J.G.P., Cardozo-Filho, L., Berezuk, M.E. (2020). Glycerol Acetylation with Propionic Acid Using Iron and Cobalt Oxides in Al-MCM-41 Catalysts. Bulletin of Chemical Reaction Engineering \& Catalysis, 15 (3), 829-844

(doi:10.9767/bcrec.15.3.9020.829-844)

Permalink/DOI: https://doi.org/10.9767/bcrec.15.3.9020.829-844

\section{Introduction}

Over the last decade, biodiesel has been suggested as a reliable renewable alternative for diesel fossil fuel; mainly due to reduced toxicity, exhaust emissions and enhancing positive carbon cycle for reduction of greenhouse gases.

\footnotetext{
* Corresponding Author.

Email: berezuk@utfpr.edu.br (M.E. Berezuk);

Tel/Fax: +554331621200
}

Therefore, reducing global climate change and global warming [1]. Biodiesel is produced from triglycerides by transesterification with short chain alcohols and a huge amount of glycerol, ca. $10 \mathrm{wt} \%$ of the overall biodiesel production, is generated as the by-product in the process [24].

Glycerol is one of the most important and promising bioderived platform chemicals from biomass and the major waste byproduct of biodiesel industry [5,6]. Glycerol (or glycerin) has 
great application in cosmetics, personal hygiene, food, medicine, and tobacco sectors [7]. In terms of chemical transformation, it still presents limited applications, the main ones on explosives production, like nitroglycerin, and in the formation of alkyd resins [8]. There is a strong motivation to produce fuels from oxygenated molecules generated from biomass conversion $[9,10]$.

Etherification reaction with alcohols, ketones, aldehydes or carboxylic acids are an important way to change glycerol molecule and promote the formation of chemical compounds that present better commercial and economic value, such as renewable fuels additives, surfactants, flavorings and solvents for use in medicine as well as anti-bacterial agents [1115].

Functionalizing of glycerol with carboxylic acid, acetic acid or propionic acid, for example, produce glycerol esters that have been identified as valuable replacement of fuel additives that are related to depleted sources, price uncertainty and environmental concern of petroleum feedstock [9]. Mono-, di- and tri-acetyl glycerides (MAG, DAG, and TAG) are the main products from the acetylation/propylation of glycerol with acetic or propionic acids and application to fuel additives to improve cold flow, reduce viscosity in biodiesel use and antiknock additives of gasoline [9,13]. Moreover, these glycerol derived products are important building blocks of greener polyester for biorefinery industry [16].

Several studies have been published related to glycerol acetylation with acetic acid using heterogeneous catalysts that enrich both Brønsted and Lewis acidic sites. Acid zeolites, acid clays, modified molecular sieves, heteropoly acids, metal oxides, ion exchange resins, among others, with modifications in their chemical structures, are being responsible for increasing the number of acidic sites that were employed in the production of acetyl glycerides [17-26]. Heterogeneous acidic catalysts showed gains in glycerol functionalization towards derived products. Possibilities of better separation stages, reuse of catalysts or regeneration presents advanced to macroscale process in industry [11,27].

According to Trifoi et al. [28], industrial catalysts must have special requirements to the catalyst's projects, for example, it's not recommended to be very sensitive to poisoning and impurities, it's important to allow a huge capacity of production, get cheap structures and metals, have thermal and mechanical resistance and be recyclable. MCM-41 molecular sieves present all those characteristics, related to applications in industry, and not only added the possibility to incorporate trivalent atoms (Al, Fe, Ga) but also other transition metals ( $\mathrm{Sn}, \mathrm{Zn}, \mathrm{Ir}$ ) in the porous / walls of the MCM-41 that promotes Lewis and Brønsted acidic sites environment functionalizing reaction mechanisms and improving selectivity and yields [8,29-34].

Some papers have highlighted the application of iron and cobalt oxides supported on zeolites or molecular sieves in the acetalization or acetylation of glycerol [21,35-36]. These metals were able to modify and promote glycerol functionalization in esters of great commercial value.

The large number of published works related the use of acetic acid in glycerol acetylation contrasts with small number of studies using propionic acid in reactions of glycerol propylation. This fact opens more horizons for scientific research. The oldest works found dated from the 1930s with homogeneous catalysis in obtaining mono-, di- and tri-propyl glycerides [37-38]. Cho et al. [39] carried out reactions for glycerol transformation with different dicarboxylic acids to obtain esters derived from glycerol. Rathod and collaborators [40] studied the esterification of propionic acid with isopropyl alcohol, observing feasibility in the production of its derived esters. Recently, Saengarum et al. [41] published scientific work which studied the glycerol propylation with propylene and 1butene hydrocarbons to obtain mono-, di- and tripropyl glycerol ethers to use as fuel additives. Commercial acid resins were employed as catalysts, corroborating that acid catalysis favored an increase in reaction yield.

Acidic routes favored acetylation glycerol reactions mostly by the use of acetic acid but rare published information presented glycerol acetylation with propionic acid, which characteristics could improve new green molecules. Iron and cobalt oxides present themselves as materials with a great acid capacity according to Pearson's theory of hard and soft acids, and this acid capacity of these metals has been little explored in the glycerol transformation.

In this context, our studies present novelty in perform acetylation reactions of glycerol with propionic acid, an important underexplored molecule to form mono-, di-, and tripropyl glycerides (MPG, DPG, and TPG). Our proposal is to functionalize this reaction with catalysts containing acidic characteristics promoted by Al-MCM-41 containing iron and cobalt oxides applied to improve glycerol chemistry transformations. 


\section{Materials and Method}

\subsection{Materials}

Glycerol (99\%, Synth Inc., Brazil), propionic acid (99\%, Vetec Chemical Inc., Brazil), methanol (99.5\%, Dinâmica Chemical Inc., Brazil), sodium chloride and sodium hydroxide (Vetec Chemical Inc., Brazil), sodium metasilicate pentahydrate and aluminum sulfate hydrate (99\%, Êxodo Scientific Inc., Brazil), cobalt(II) nitrate hexahydrate (99\%, Dinâmica Chemical Inc., Brazil), iron(III) nitrate nonahydrate (99\%, Vetec Chemical Inc., Brazil), cetyl trimethyl ammonium bromide (CTAB, 99\%, SigmaAldrich, US) and sulfuric acid (95-98\%, Hexis Scientific, Brazil) are from an analytical standard used without prior treatment. Monoethylene glycol (99\%, Vetec Chemical Inc., Brazil) was used as an internal standard for gas chromatography (GC) analyses. Magnetic and mechanic stirrer with heating control, $\mathrm{pH}$ meter and a variety of different glassware were also used.

\subsection{Preparation of Catalysts}

Al-MCM-41 template structure was prepared by sol-gel method described by Heravi et al. [31] and Preethi et al. [42] with modifications. Molecular sieves molar compositions defined for the catalysts template were $\mathrm{SiO}_{2}: \mathrm{xAl}_{2} \mathrm{O}_{3}: 0.2 \mathrm{CTAB}: 0.89 \mathrm{H}_{2} \mathrm{SO}_{4}: 120 \mathrm{H}_{2} \mathrm{O}$ which results in two different $\mathrm{Al} / \mathrm{Si}$ ratios $1 / 5$ and $1 / 25$.

Briefly, sodium metasilicate (38 g) and aluminum sulfate $(11.25 \mathrm{~g}$ and $2.25 \mathrm{~g})$ were dissolved in a beaker with distilled water in magnetic stirrer for $1 \mathrm{~h}$. Aluminum solution was slowly mixed with silicon solution and stirred by 30 minutes to homogenize. Sulfuric acid solution was added to mother liquor solution drop by drop until reach $\mathrm{pH} 10.5$ resulting in a gel texture appearance in the solution. After $\mathrm{pH}$ adjustment, CTAB solution was prepared and added slowly to the gel mixture with mechanic stirrer keeping it in movement by an hour. The gel material formed was transferred to Tefloncoated autoclaves vessels to age the solution and kept in an air-drying lab oven at $145^{\circ} \mathrm{C}$ for 40 hours. Then the solid product obtained was filtered, washed several times with distilled water and dried at $95{ }^{\circ} \mathrm{C}$ in an air-drying oven for $2 \mathrm{~h}$. Then the sample was calcined in a muffle furnace at $550{ }^{\circ} \mathrm{C}$ for $15 \mathrm{~h}\left(0.7{ }^{\circ} \mathrm{C} \cdot \mathrm{min}^{-1}\right.$ ramp rate) to remove the template.

To maximize Brønsted acidic sites in $\mathrm{Al}$ MCM-41 an ion exchange procedure was done mixing the obtained white powder with a solu- tion of ammonium chlorate (1 M), twice times. This mixture was kept in magnetic stirring for 24 hours in room temperature. Solution was filtered, dried and calcined again at $550{ }^{\circ} \mathrm{C}$ for 4 $\mathrm{h}$ in air atmosphere.

Iron and/or cobalt metals were added to $\mathrm{Al}$ MCM-41 materials by incipient wetness impregnation method described by Decyk et al. [43]. After determining the apparent volume of the Al-MCM-41 in a graduate beaker, a volume 10 times greater were used to prepare the solution. Iron(III) nitrate hexahydrate and/or cobalt(II) nitrate nonahydrate were dissolved in distillate water to provide $10 \mathrm{wt} \%$ total metal in catalysts. The solution was kept in magnetic stirrer for 1 hour and then the material temperature was raised to $70{ }^{\circ} \mathrm{C}$ for a period of 6 hours, until the material dried. After material was dried at $95^{\circ} \mathrm{C}$ in an air-drying oven for $3 \mathrm{~h}$ and calcined in a muffle furnace at $550{ }^{\circ} \mathrm{C}$ for 4 h. Six different catalysts were able to test which codes were named Fe5, Fe25, Co5, Co25, $\mathrm{FeCo5}$, and $\mathrm{FeCo} 25$.

\subsection{Products Analysis}

Analysis of the reaction products identified the Shimadzu QP-2010 Ultra gas chromatography with mass detector (GC-MS), using RtxWax (Restek) column with $30 \mathrm{~m} \times 0.25 \mathrm{~mm} \times$ $0.25 \mu \mathrm{m}$. The temperature of the injector chamber was $250{ }^{\circ} \mathrm{C}$, varying the oven temperature from $40{ }^{\circ} \mathrm{C}$ to $200{ }^{\circ} \mathrm{C}$ with a rate of $10^{\circ} \mathrm{C} \cdot \mathrm{min}^{-1}$ with hold for 9 minutes in final temperature. Split dilution was used at 1:60. External standard for GC analysis was used for the quantification of glycerol and benzaldehyde. The monoethylene glycol was used as internal standard diluted on methanol in the concentration of $100 \mathrm{mg} . \mathrm{mL}^{-1}$, to products quantification.

Glycerol conversion calculations, as well as the selectivity for desired products and the final reaction yield are defined by Equations 1 to 3 [44].

Conversion $(\%)=100 \times \frac{(\text { initial mols reagent }- \text { final mols reagent })}{\text { initial mols reagent }}$

Selectivity $(\%)=100 \times \frac{\text { desired mols product }}{(\text { initial mols reagent }- \text { final mols reagent })}$

Yield $(\%)=\frac{\text { Conversion }(\%) \times \text { Selectivity }(\%)}{100}$ 


\subsection{Reactional Experiments}

The experiment was conducted through etherification of glycerol with propionic acid in $50 \mathrm{ml}$ borosilicate glass batch sealed reactors, without use of organic solvents. Moreover, to control the reaction solution, externalcontrolled hotplates with external thermostat and a magnetic vigorous stirring system were used to avoid or diminish mass and heat transfers resistances. Besides that, the reactor was not attached to the reflux condenser in order to remove excess water from the reaction solution.

In a typical reaction procedure, $25 \mathrm{mmol}$ of glycerol $(2.3 \mathrm{~g})$ was added with $125 \mathrm{mmol}$ of propionic acid (9.26 g) (related to 1/5 glycerol / acid ratio). The use of $100 \mathrm{mg}$ of catalyst per test was fixed and the reaction time varied from 2 to 4 hours. Besides that, five temperatures ranging from $90{ }^{\circ} \mathrm{C}$ until $140{ }^{\circ} \mathrm{C}$, and the ratio of glycerol to propionic acid were observed always with acid excess in reaction medium. At the end of the reactions, an amount of material was filtered on qualitative filter papers (grade 4) with cotton, collected in $2 \mathrm{~mL}$ vials and stored in a freezer. All experiments were per-

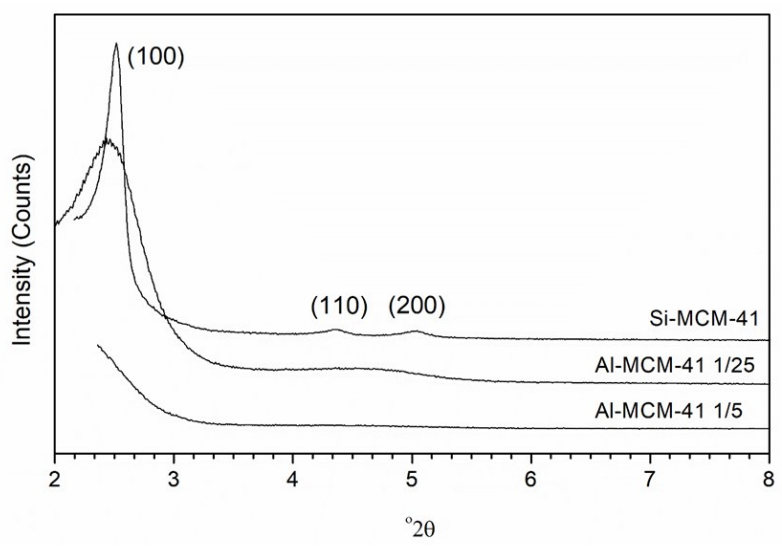

Figure 1. Low angle XRD patterns for catalyst precursors.

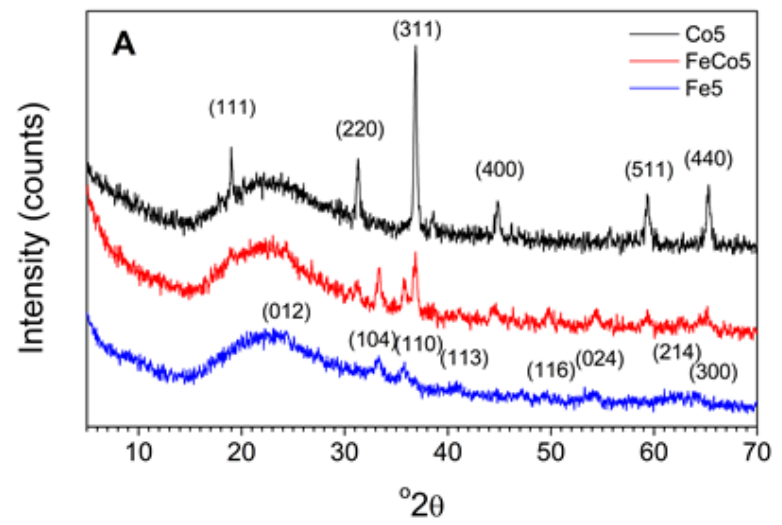

formed in duplicate form. Reaction conditions exploited was chosen according to literature researches $[12,45]$.

\subsection{Instrumentation}

The X-ray diffraction (XRD) patterns of molecular sieves synthesized catalysts were obtained by using a Bruker powder diffractometer D2 PHASER model using $\mathrm{Cu}-\mathrm{K} \alpha$ radiation, nickel filter, $10 \mathrm{~mA}$ and $30 \mathrm{kV}$ in the high voltage source, and scanning angle between $10^{\circ}$ and $70^{\circ}$ of $2 \theta$ with $0.02^{\circ}$ steps per second. Adsorption/desorption experiments using $\mathrm{N}_{2}$ were carried out at $77 \mathrm{~K}$ on a Quantachrome NOVA 1200 instrument. Before each measurement the samples were first outgassed at $423 \mathrm{~K}$ for $12 \mathrm{~h}$ at $5 \times 10^{-3}$ Torr and then at room temperature for $2 \mathrm{~h}$ at $1 \times 10^{-5}$ Torr. The $\mathrm{N}_{2}$ isotherms were used to determine the specific surface areas, pore volume, and pore diameter using the BET equation and BJH theory. Infrared spectra were collected on a FTIR Bruker model Vertex 70 spectrophotometer, with $\mathrm{KBr}$ as dispersant and the spectra was recorded from 400 $\mathrm{cm}^{-1}$ to $4000 \mathrm{~cm}^{-1}$ with a resolution of $4 \mathrm{~cm}^{-1}$ and total of 10 scans. X-ray Fluorescence spectroscopy (XRF) analysis was recorded by Rigaku Supermini 200 using Pd X-ray tube with $50 \mathrm{kV}$ voltage and $4 \mathrm{~mA}$. Catalysts were also characterized using scanning electron microscopy (SEM) with a Shimadzu scanning electron microscope model SSX-550 Superscan with an accelerating voltage of $30 \mathrm{kV}$ and different magnifications.

\section{Results and Discussion}

\subsection{Characterization}

X-ray diffraction patterns of calcined mesoporous Al-MCM-41 precursors and $\mathrm{Fe} / \mathrm{Co}-\mathrm{Al}-$ MCM-41 catalysts samples are shown in Figure 1 and 2. At low angle X-ray diffraction pat-

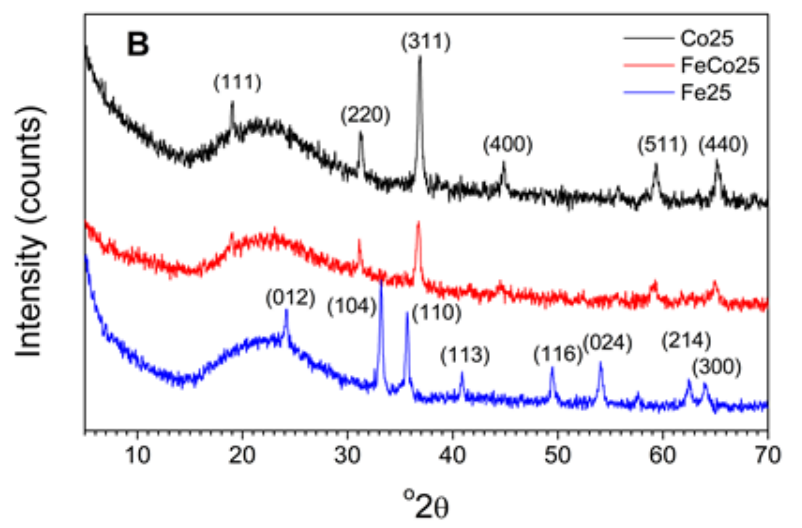

Figure 2. XRD patterns of the Sn-Al-MCM-41 catalysts samples in the domain of 10-70 (20). 
terns exhibit typical MCM-41 signs with strong peak in the $2 \theta$ range of $2-3-2.6^{\circ}$ due to (100) reflection lines but as larger amounts of aluminum are present in the structure this (100) reflection present peaks going broader and less intense. High $\mathrm{Al}$ content in MCM-41 contributes to diminish orderly the structural pore channels and the main intense peak shifts towards higher interplanar spacing and this behavior represents an increase in the pore size of the MCM-41 material [46-47,59]. This modified interplanar spacing can be explained about of replacement of shorter $\mathrm{Si}-\mathrm{O}$ bonds $(1.60 \AA)$ by longer A1-O bonds (1.75 $\AA$ ) in the MCM- 41 structure [59]. Other Miller's indices (110) and (200) also presents same behavior and the welldefined peaks disappears to form a broad peak

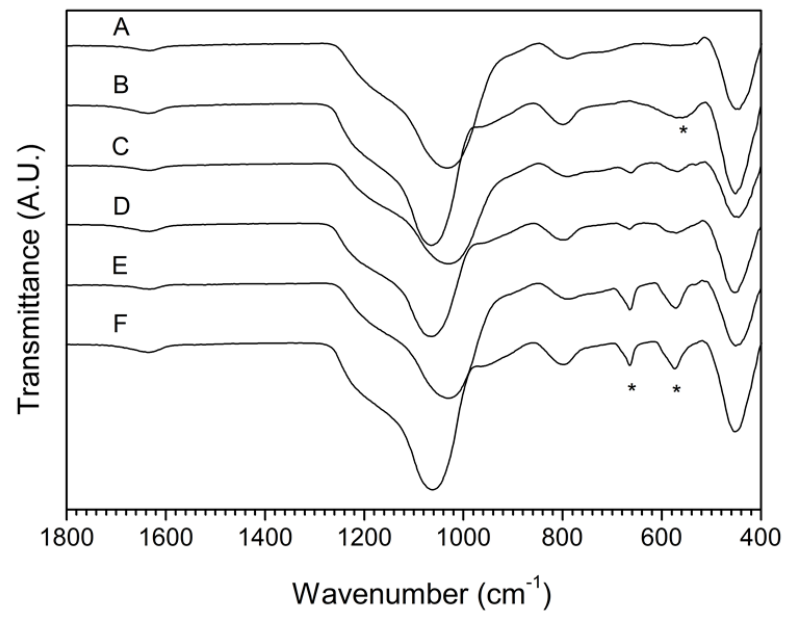

Figure 3. FT-IR spectra for synthesized catalysts. A) Fe5, B) Fe25, C) FeCo5, D) FeCo25, E) Co5 and F) Co25. in $\mathrm{Si} / \mathrm{Al}$ in $1 / 25$ and totally disappears in $1 / 5$. The $d_{100}$ spacing, lattice parameter $\left(a_{0}\right)$, and Scherrer calculated values are presented in Table 1.

In Figure 2, a typical iron(III) oxide $\left(\mathrm{Fe}_{2} \mathrm{O}_{3}\right)$ and cobalt(II,III) oxides $\left(\mathrm{CoO} . \mathrm{Co}_{2} \mathrm{O}_{3} \rightarrow \mathrm{Co}_{3} \mathrm{O}_{4}\right)$ diffractogram peak patterns from $\mathrm{Fe} / \mathrm{Co}-\mathrm{Al}-$ MCM-41 samples are observed by the Miller indices. Spinel phase of cubic $\mathrm{Co}_{3} \mathrm{O}_{4}$ crystalline cell patterns are presented in the all cobalt synthesized catalysts and hematite hexagonal $\mathrm{Fe}_{2} \mathrm{O}_{3}$ crystalline cell patterns are showed in all iron synthesized catalysts [48-49]. No other phases/shift in peak positions were observed by XRD in this study which suggests that no extensive solid solution was formed between the two oxides as a result of this preparation catalyst impregnation method.

Iron and cobalt oxides presented different crystallite dimensions calculated by Scherrer equation [50-51], while $\mathrm{Co}_{3} \mathrm{O}_{4}$ crystals showed increased dimensions if compared with $\mathrm{Fe}_{2} \mathrm{O}_{3}$ crystals (Table 1). This behavior is repeated even when the concentration of iron and cobalt elements are reduced by half in the catalysts $\mathrm{FeCo} 5$ and FeCo25. Unfortunately, no iron signal can be seen on FeCo25 sample patterns.

Figure 3 reports the FT-IR spectra for all $\mathrm{Fe}$ and Co synthesized catalysts in $1800-400 \mathrm{~cm}^{-1}$ range. In all sample's curves, the band in 1640 $\mathrm{cm}^{-1}$ correspond to the $\mathrm{vo}-\mathrm{H}$ vibrations of silanol groups [52], while strong bands around 1230 and $1060 \mathrm{~cm}^{-1}$ correspond to $\mathrm{U} \equiv \mathrm{S} \mathrm{S}-\mathrm{O}-\mathrm{S} \mathrm{S} \equiv$ and USi-O-Si asymmetric stretching, typical for MCM-41. Curves A, C and E, which correspond to $\mathrm{Fe} 5, \mathrm{FeCo} 5$ and $\mathrm{Co} 5$ catalyst, have a structure with higher $\mathrm{Al}$ content, then this behavior

Table 1. Textural analysis and metal loading percentage.

\begin{tabular}{lccccc}
\hline \multicolumn{1}{c}{ Materials } & Si/Al & Angle $\left({ }^{\circ} 2 \theta\right)^{\mathrm{a}}$ & $d_{100}(\AA)^{\mathrm{b}}$ & $\mathrm{a}_{0}(\AA)^{\mathrm{c}}$ & $D_{\text {sc }}(\AA)^{\mathrm{e}}$ \\
\hline Si-MCM-41 & - & 2.5 & 35.0 & 40.1 & - \\
Al-MCM-41 & $1 / 5$ & 2.3 & 38.7 & 44.7 & - \\
Al-MCM-41 & $1 / 25$ & 2.4 & 36.3 & 41.9 & - \\
Fe5 & $1 / 5$ & 33.2 & 2.7 & 2.2 & 36 \\
$\mathrm{Fe} 25^{\mathrm{d}}$ & $1 / 25$ & 33.2 & 2.7 & 2.2 & 71 \\
$\mathrm{Co} 5^{\mathrm{d}}$ & $1 / 5$ & 36.9 & 2.4 & 2.0 & 108 \\
$\mathrm{Co} 25^{\mathrm{d}}$ & $1 / 25$ & 36.9 & 2.4 & 2.0 & 108 \\
$\mathrm{FeCo5}^{\mathrm{d}}$ & $1 / 5$ & $33.4 / 36.9$ & $2.7 / 2.4$ & $2.2 / 2.0$ & $53 / 86$ \\
$\mathrm{FeCo}^{\mathrm{d}}$ & $1 / 25$ & $-/ 36.9$ & $-/ 2.4$ & $-/ 2.0$ & $-/ 48$ \\
\hline
\end{tabular}

a Miller index (100) for molecular sieves precursors, (104) for Fe catalysts and (311) for Co catalysts.

b Interplanar spacing parameter.

c Lattice crystal parameter: $\mathrm{a}_{0}=2 \mathrm{~d}_{100} / 3^{0.5}$.

d Parameters referring to the $\mathrm{Fe}_{2} \mathrm{O}_{3}$ and $\mathrm{Co}_{3} \mathrm{O}_{4}$ crystals.

e Mean size diameter for crystallites $\mathrm{Fe}_{2} \mathrm{O}_{3}$ and $\mathrm{Co}_{3} \mathrm{O}_{4}$ sites by Scherrer Equation calculation [51]. 
shifts in approximately $30 \mathrm{~cm}^{-1}(1060-1030$ $\mathrm{cm}^{-1}$ ) the siloxane bands, this shifting band occurs due to $\mathrm{SiO}_{4}$ and $\mathrm{AlO}_{4}$ tetrahedral simultaneous vibrations [53]. The band around 970 $\mathrm{cm}^{-1}$ correspond to a vibration mode of $\mathrm{SiO}_{4}$ perturbed by the presence of neighboring $\mathrm{Fe}_{2} \mathrm{O}_{3} / \mathrm{Co}_{3} \mathrm{O}_{4}$ or $\mathrm{Fe}=\mathrm{O}(\mathrm{OH}) / \mathrm{Co}=\mathrm{O}(\mathrm{OH})$ group. The presence of this band is attributed to the formation of USi-O-Si linkages in metallosilicates [54]. Symmetric vibrations USi-O-Si signs appear near $800 \mathrm{~cm}^{-1}$. The band at $450 \mathrm{~cm}^{-1}$ may be assigned to USi-O tetrahedral vibration [55]. The UFe-O-Fe stretching vibration, characteristic of $\mathrm{Fe}_{2} \mathrm{O}_{3}$ is observed at approximately $560 \mathrm{~cm}^{-1}$ and $\mathrm{U}_{\mathrm{Co}-\mathrm{O}-\mathrm{Co}}$ stretching vibration, characteristic of $\mathrm{Co}_{3} \mathrm{O}_{4}$ is observed approximately $573 \mathrm{~cm}^{-1}$ and $670 \mathrm{~cm}^{-1}$ [56-58].

The results of the chemical analysis of the catalysts are given in the Table 2 and adsorption/desorption isotherms curves are presented

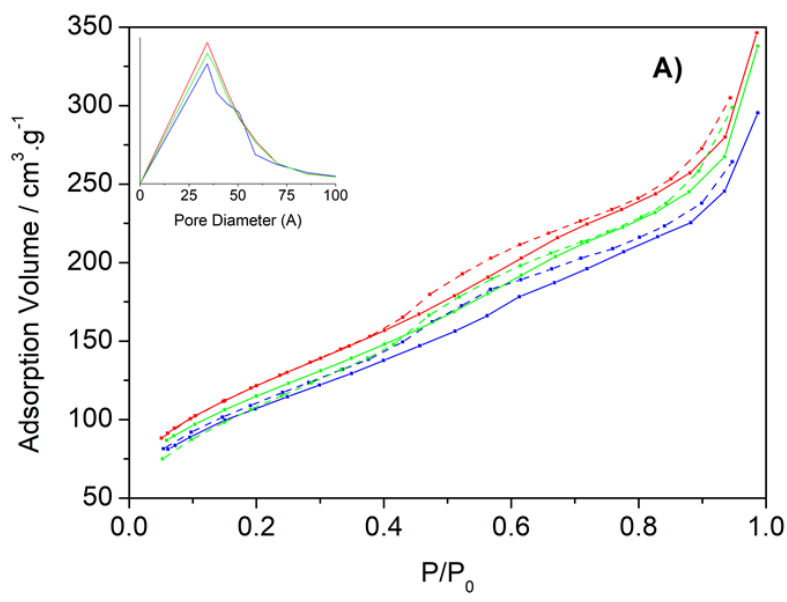

in Figure 4. Classic MCM-41 molecular sieves isotherms type IV which represents mesoporosity materials are observed when $\mathrm{Al} / \mathrm{Si}$ ratio are $1 / 25$ which curves shows a smaller hysteresis behavior due to capillary condensation of $\mathrm{N}_{2}$ in the primary mesopores. Increasing the presence of $\mathrm{Al}$ in $\mathrm{MCM}-41$ to provide $\mathrm{Al} / \mathrm{Si}$ in $1 / 5$ parts disorder the structure modifying interplanar spacing, lattice crystal parameters and had consequences for diminish strongly the surface area and pore volume. The enlargement of the unit cell observed by lattice crystal parameters by the presence of high $\mathrm{Al}$ content followed by addition of iron and/or cobalt oxides in the pores structure aimed to these behaviors in MCM-41 [59-61]. Fe5, FeCo5, and Co5 catalysts isotherms clearly shows poor crystallinity compared to $\mathrm{Fe} 25, \mathrm{FeCo} 25$, and Co25 [30,59].

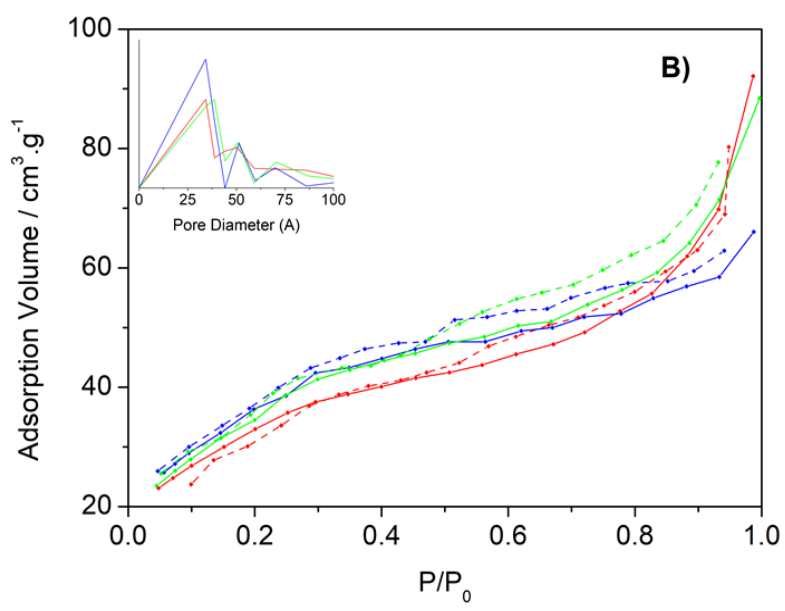

Figure 4. Adsorption / desorption isotherms for the catalysts. A) $\mathrm{Al} / \mathrm{Si}$ ratio in $1 / 25$ and $\mathrm{B}$ ) $\mathrm{Al} / \mathrm{Si}$ ratio in 1/5. Legend: $\mathrm{Fe} 25$ or Fe5, Co25 or Co5, FeCo25 or FeCo5. Line and symbol are Adsorption points, Dash and symbol are Desorption points.

Table 2. XRD parameters for the synthesized materials.

\begin{tabular}{llcccccc}
\hline Catalysts & & Fe5 & FeCo5 & Co5 & Fe25 & FeCo25 & Co25 \\
\hline Surface Area $\left(\mathrm{m}^{2} \cdot \mathrm{g}^{-1}\right)$ & Micro $^{\mathrm{a}}$ & 57 & 74 & 95 & 175 & 152 & 162 \\
& Meso and External $^{\mathrm{a}}$ & 63 & 58 & 39 & 261 & 259 & 222 \\
& Total $^{\mathrm{a}}$ & 120 & 132 & 135 & 436 & 411 & 384 \\
& Micro $^{\mathrm{a}}$ & 0.024 & 0.031 & 0.043 & 0.090 & 0.074 & 0.086 \\
Pore Volume $\left(\mathrm{cm}^{3} \cdot \mathrm{g}^{-1}\right)$ & 0.074 & 0.060 & 0.058 & 0.316 & 0.341 & 0.250 \\
& Meso & 0.098 & 0.091 & 0.101 & 0.406 & 0.415 & 0.336 \\
& Total $^{\mathrm{b}}$ & 34.2 & 36.3 & 34.2 & 34.4 & 35.6 & 36.3 \\
Mean Pore Diameter $(\AA)^{\mathrm{b}}$ & & 9.65 & 4.77 & - & 9.52 & 4.68 & - \\
Fe Load $(\%, \mathrm{~m} / \mathrm{m})^{\mathrm{c}}$ & & - & 4.94 & 10.21 & - & 4.88 & 9.75 \\
Co Load $(\%, \mathrm{~m} / \mathrm{m})^{\mathrm{c}}$ & & & & & & &
\end{tabular}

a The $t$-Plot method were used to obtain micropores e meso-external surface area data.

b BJH method were used to determine mean pore diameter and total pore volume.

c Metal Fe and Co content were obtained by XRF analysis. 


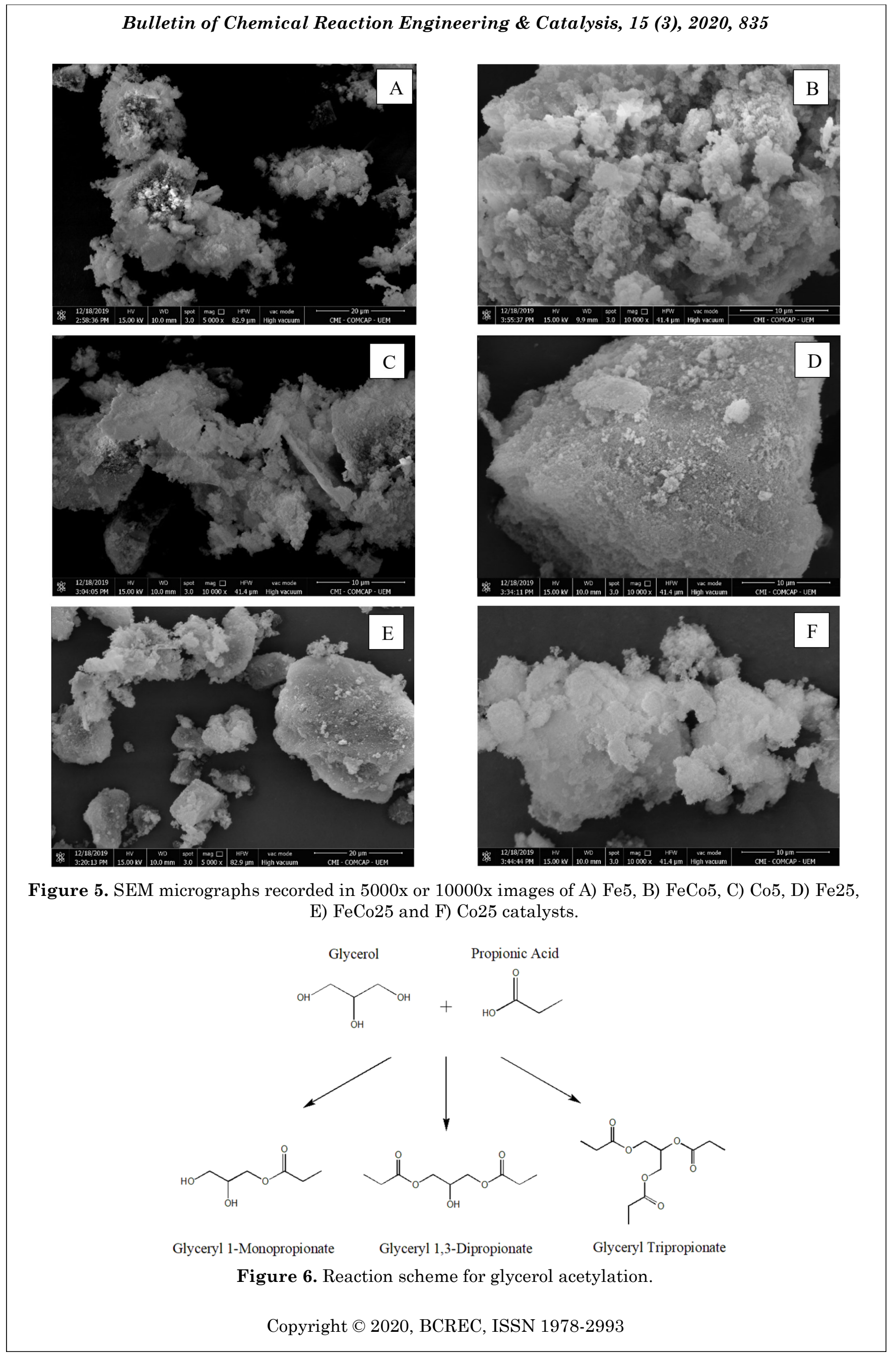


Figure 5 shows scanning electronic microscopy images (SEM) for all synthesized catalysts. All catalysts sample presented spherical small crystallites alternating between welldefined structures to greater particle nonuniform clusters. This morphology characteristics is typical for Al-MCM-41 and the more aluminum is inserted into the MCM-41 matrix structure itself, the greater the tendency to observe a more dispersed material containing a less defined morphology [52,62-64].

\subsection{Glycerol Etherification Reactions}

$\mathrm{Fe} / \mathrm{Co}-\mathrm{Al}-\mathrm{MCM}-41$ catalysts were tested in the etherification reactions of glycerol with propionic acid. We considered the formation of Glyceryl 1-Monopropionate (MPG), Glyceryl 1,3-Dipropionate (DPG), and Glyceryl Tripropionate (TPG) as desired major products, besides that, the formation of Ethylene Glycol Dipropi-

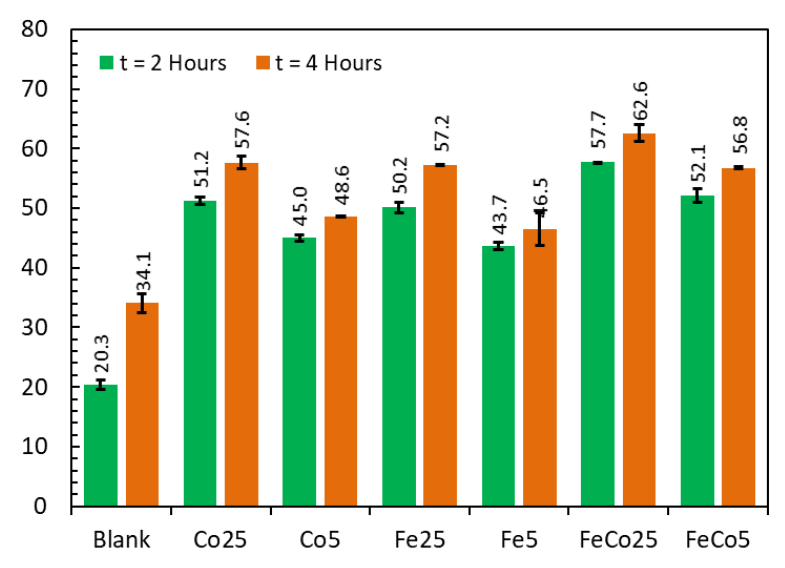

Figure 7. Reaction yield (\%) to MPG product.

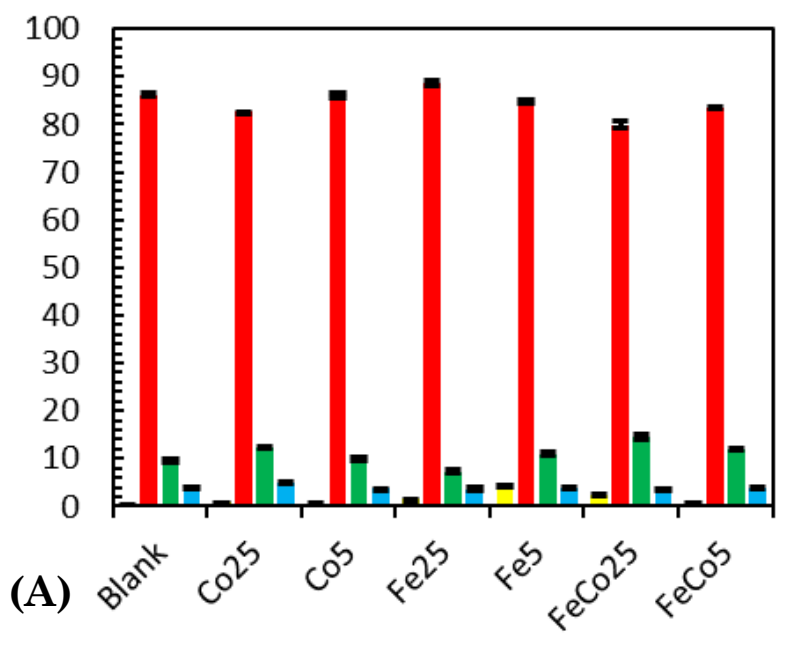

onate as undesired product. Diglycerol also could be formed but no GC-MS signal detected the presence on chromatograms (Figure 6).

In the first stage of experiments, all six catalysts were applied in reactions where the temperature was set at $110{ }^{\circ} \mathrm{C}$, the glycerol/acid ratio was $1 / 5$ (propionic acid excess) and the catalyst mass was $100 \mathrm{mg}$ per test, all in duplicate. Catalysts were evaluated for $2 \mathrm{~h}$ and $4 \mathrm{~h}$. Figure 7 and Figure 8 shows the reaction yield in relation to glyceryl 1-monopropionate (MPG) product, in addition to the selectivity for all the products observed.

Catalysts that have both iron oxides and cobalt oxides were shown to be more active compared to catalysts that contain only one of the metal oxides. Catalysts with cobalt oxides have higher conversion values compared to catalysts with iron oxides. Catalysts with a high aluminum content $(\mathrm{Al} / \mathrm{Si}=1 / 5)$ showed lower conversion values compared to catalysts with a lower concentration of this metal in the matrix of MCM-41 ( $\mathrm{Al} / \mathrm{Si}=1 / 25)$. The available surface area for catalysis is an important factor for a better reaction performance and this characteristic proved to be more relevant, even with the presence of a higher concentration of aluminum atoms in the framework or extraframework. The insertion of $\mathrm{Al}$ can offer more Lewis acid sites to the catalysts surface and alters the structure of silicates to offer Brønsted sites according to the Löwenstein rule [65-66]. MPG product proved to be the main molecule obtained with selectivity between 78 to $90 \%$ and, as the conversion values increase, also does the formation of DPG and TPG, but on a still low scale, up to $15 \%$ selectivity for DPG

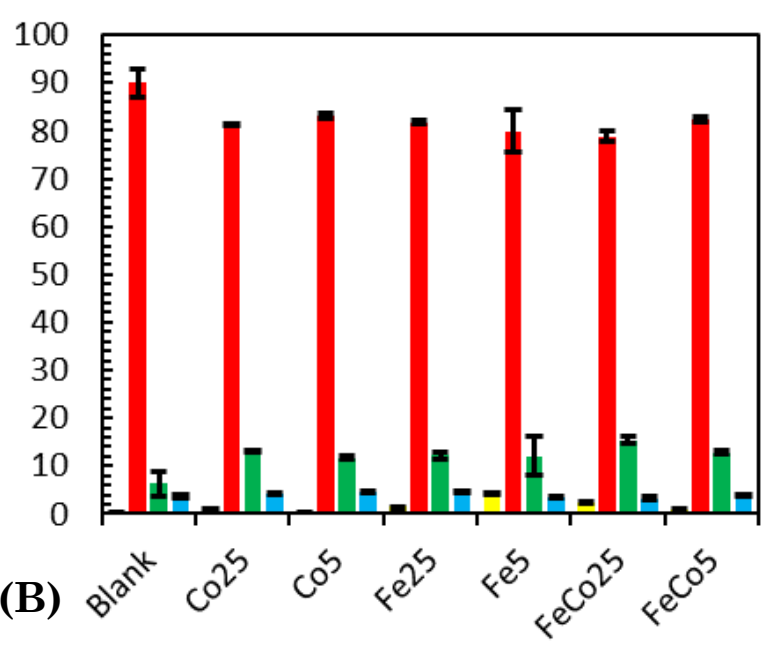

Figure 8. Selectivity (\%) to all reaction products observed in (A) 2 hours and (B) 4 hours of reaction. Legend: - Glyceryl Tripropionate, - Glyceryl 1-Monopropionate, • Glyceryl 1,3-Dipropionate, = Ethylene Glycol Dipropionate. 
and only $5 \%$ for TPG. The by-product Ethylene Glycol Dipropionate was also observed in up to $5 \%$ selectivity. Despite the lower conversion value, $\mathrm{Fe} 5$ catalyst was the only material that favored the formation of TPG, under the conditions presented. It is possible that the more acidic characteristics of the catalyst together with the hard acid dynamics of iron oxide may favor the achievement of TPG. After 4 hours of reaction, yields above $60 \%$ were obtained in acetylation of glycerol with propionic acid, at a temperature of only $110{ }^{\circ} \mathrm{C}$, which shows that the use of the molecular sieve Al-MCM-41 containing iron and cobalt is important to functionalize glycerol towards values green products.

It is observed that there is a junction between the catalysts acidic characteristics associated with the surface area availability for chemical contact of the catalysis sites with the reagents (Table 2). The synthesis of Al-MCM41 and its modification to maximize acidic sites of both Lewis and Brønsted sites are shown to be present in all catalysts. However, the insertion of iron and cobalt metals is the key point for the increase conversion and yields (Figure 7). The concept of acidity provided by transition metals is best explained by the Theory of Hard and Soft Acids by Ralph Pearson [67]. Pearson defined species more polarizable as soft (acid or base) and less polarizable as hard (acid or base). The hardness or softness value can be determined using the values of ionization potential and electronic affinity of these species [68]. XRD analysis showed the presence of $\mathrm{Fe}^{3+}$ and $\mathrm{Co}^{3+} / \mathrm{Co}^{2+}$ in the form of oxides of different nanometric sizes (36-108 $\AA$, Table 1) and the trivalent metals are classified as hard acids (higher acidity index) and the divalent metal as

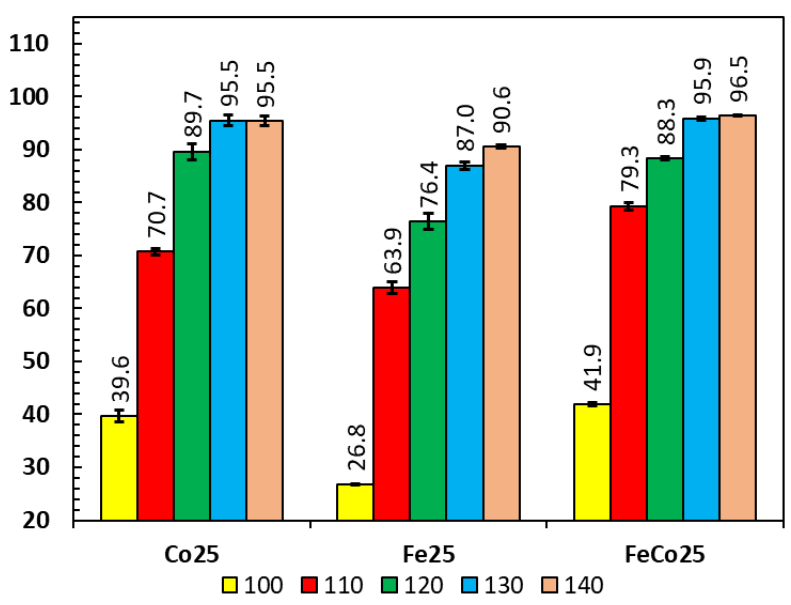

Figure 9. Glycerol conversion (\%) with varying temperature $\left({ }^{\circ} \mathrm{C}\right)$. a characteristic intermediate acid. In this sense, the presence of these metals is strongly beneficial in the glycerol acetylation with propionic acid.

\subsection{Temperature Reaction Dependence}

In this second stage, the reaction temperature varied, while the other parameters were kept constant, to observe what would be the reaction behavior with increasing temperature. Moreover, only the catalysts that showed the highest reaction yield in the first test stage were used: Fe25, Co25, and FeCo25. It was observed that the reaction depends strongly of the increase of the temperature from $100{ }^{\circ} \mathrm{C}$ (Figure 9), and glycerol conversion tends to stabilize close to $95 \%$ from $130{ }^{\circ} \mathrm{C}$. In this way, a temperature of $140{ }^{\circ} \mathrm{C}$ did not prove to be advantageous for significantly increasing of glycerol conversion values. Catalysts containing cobalt showed to be more active than iron, reaching higher conversion values as the temperature increased.

The maximum MPG yield is reached at 130 ${ }^{\circ} \mathrm{C}$ (approximately 68\%) and has a slight decline at $140{ }^{\circ} \mathrm{C}$ (Figure 10). Again, a greater formation of TPG (13.1\%) occurs with the use of the catalyst containing iron ( $\mathrm{Fe} 25)$, a behavior observed in the first stage of experiments that can be explained by Pearson's theory, previously analyzed.

Zhang et al. [36] investigated the use of M$\mathrm{AlPO}_{4}$ zeolite containing some transition metals, including cobalt, in the acetalization reaction of glycerol with acetone. Even having a behavior of a smaller surface area and lower acidic sites characteristics compared to the best catalyst used, the cobalt containing catalyst proved to be a material capable of offering the second-best reaction yield, under the investigated conditions (yield 67\%). This result shows to be important for the use of cobalt as an active site in glycerol acetalization. A similar result was observed for the same reaction using cobalt catalysts in layered double hydroxide $(\mathrm{LDH})$, where a yield of around $70 \%$ of reaction was achieved [35].

Gonzales-Arellano et al. [21] performed glycerol acetalization with levulinic acid using Zr-SBA-16 containing different Zr levels. At $100{ }^{\circ} \mathrm{C}$ and 15 hours of reaction, his best results reached around $70 \%$ conversion, $77 \%$ selectivity for monoglycerides and $23 \%$ for diglycerides. A behavior similar to the data presented in this work. It is worth noting that the appearance of triglycerides occurred at a higher temperature after the conversion approached 


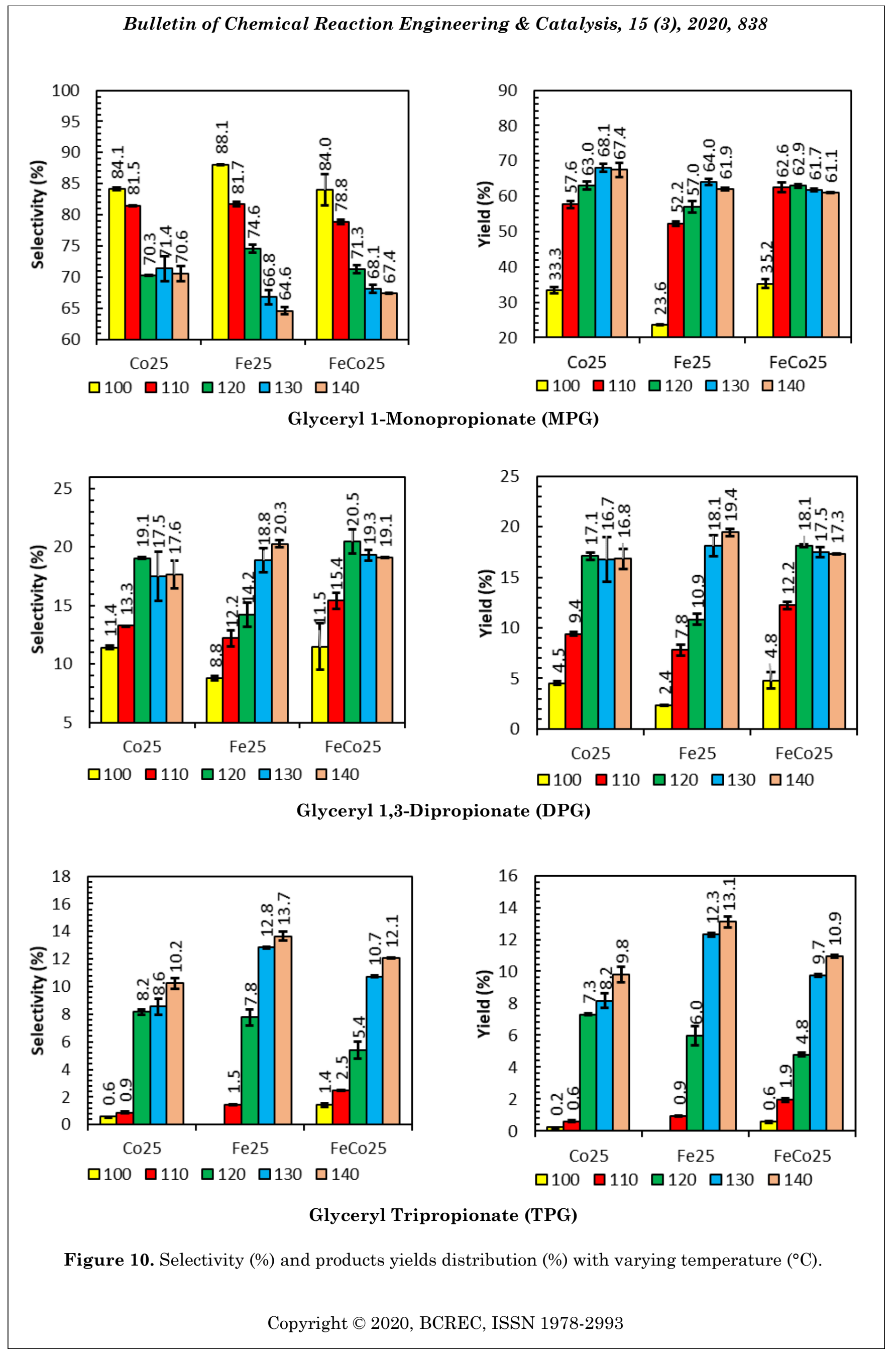


$100 \%$, which demonstrates a behavior of occurring consecutive reactions as the glycerol is depleted as a limiting reagent in the process.

Saengarum et al. [41] compared Amberlyst15 resin with commercial sulfated B100 and B200 resins by applying them in the etherification of glycerol with propylene, a molecule of size close to propionic acid. At $100{ }^{\circ} \mathrm{C}$ and 8 hours of reaction, only Amberlyst-15 resin was able to convert glycerol into mono-, di-, and triglycerol ethers with $60 \%$ conversion. As the reaction time was extended to 16,24 , and 72 hours, the sulfated resins also showed the same products reaching up to $72 \%$ conversion. The acid capacity of Amberlyst-15 favored the results obtained, but the deterioration of its molecular structure associated with the formation of coke in its pores significantly reduced its use in sequential reactions.

It is observed with the investigated works and with the experiments carried out (Figure 9
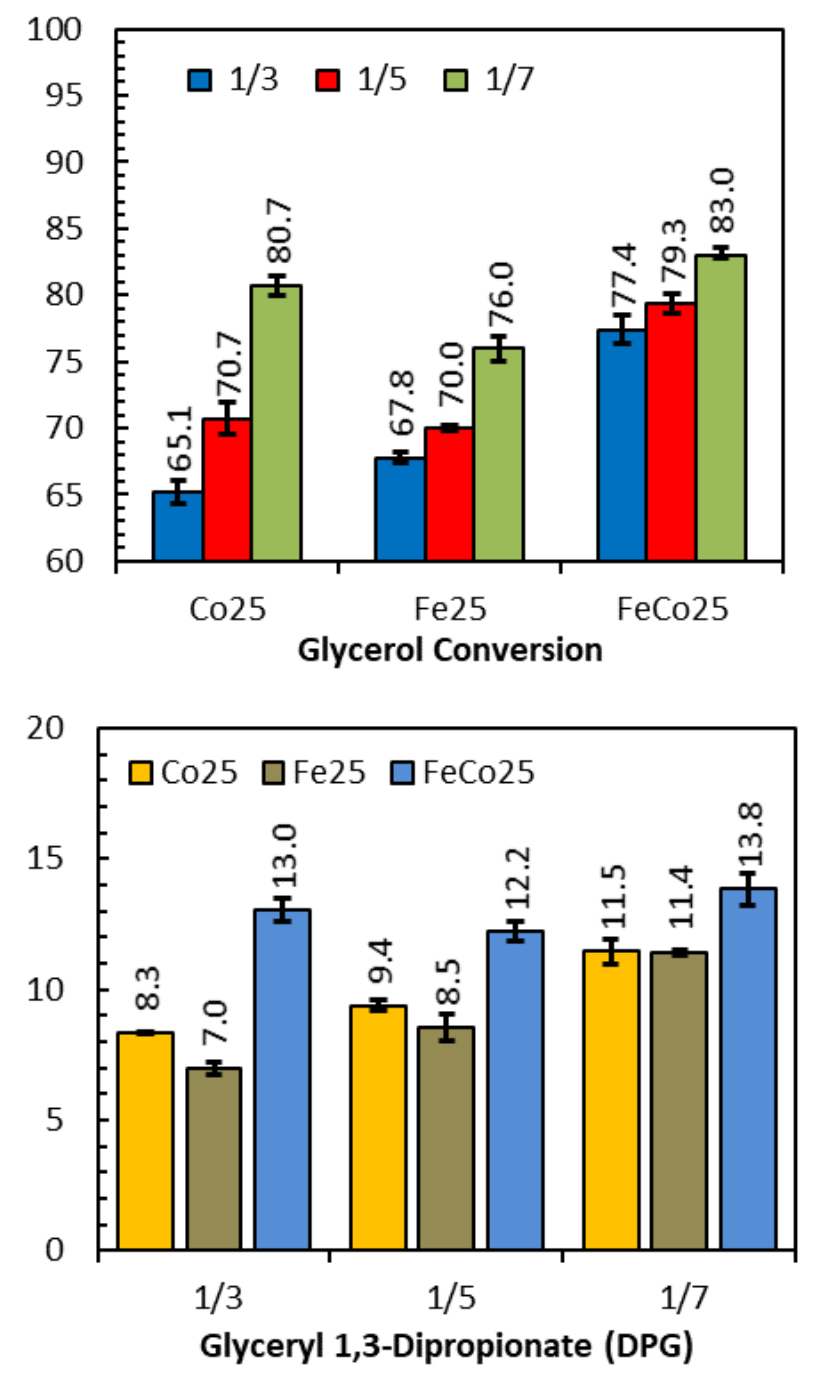

and 10) that as the reaction exhausts glycerol, DPG and TPG tends to appear in greater quantities as the reaction time and increasing temperature. The preference for the formation of the MPG is given by the easier supply of glycerol in the initial stages of reaction. When glycerol is depleting from reaction medium, the excess of propionic acid continues to react with MPG to form DPG and, likewise, to produce TPG. Acidic surface capacity associated with the availability of catalytic sites of the materials, are catalyst highlighted keys in the formation derived products from glycerol and propionic acid.

\subsection{Reagents Ratio Dependence}

Glycerol acetalization reactions with propionic acid were also carried out by changing the concentrations of reagents, keeping the temperature constant at $110^{\circ} \mathrm{C}$, as well as other
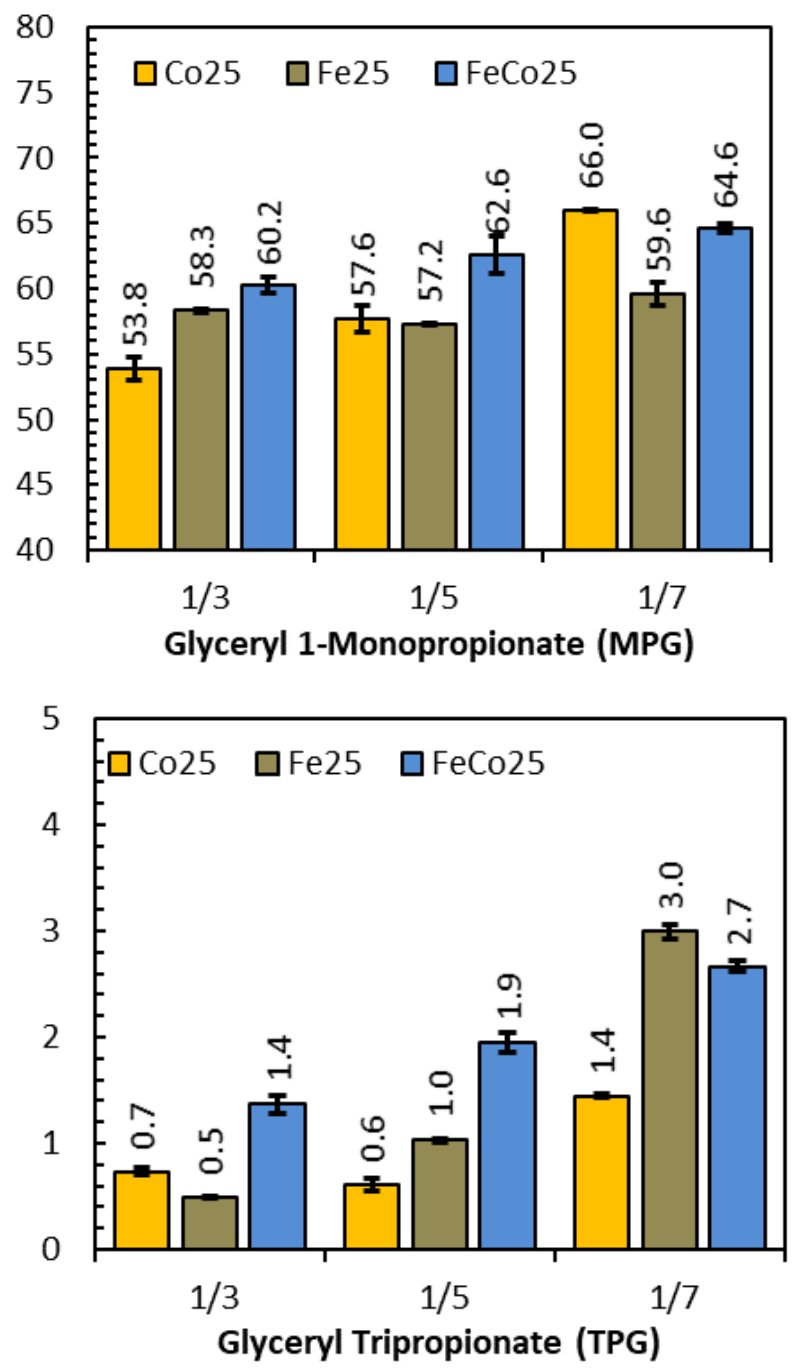

Figure 11. Glycerol conversion (\%) and products yields (\%) in different glycerol / propionic acid ratios and catalysts. 
constant parameters. Reactions containing the excess acidic conditions in the Glycerol / Acid ratio in $1 / 3,1 / 5$ and $1 / 7$ were analyzed.

It is noted that the increase in propionic acid concentration shifted the reaction to the products (Figure 11), increasing the glycerol conversion for all catalysts tested and favoring the consecutive reactions to form DPG and TPG. It can also be seen that the Co25 catalyst favored the formation of MPG more, reaching a yield of up to $66 \%$ with a corresponding selectivity of $81.8 \%$ (Figure 12). Fe25 catalyst was more inclined to form TPG, but was less effective in converting glycerol, which reduced its final yield values. The FeCo25 catalyst proved to be more versatile in forming DPG, but its high conversion was responsible for having the best reaction yield values. As the general characteristics of all catalysts are very close, the differences in selectivity and final reaction yield are also similar. However, all materials tested were
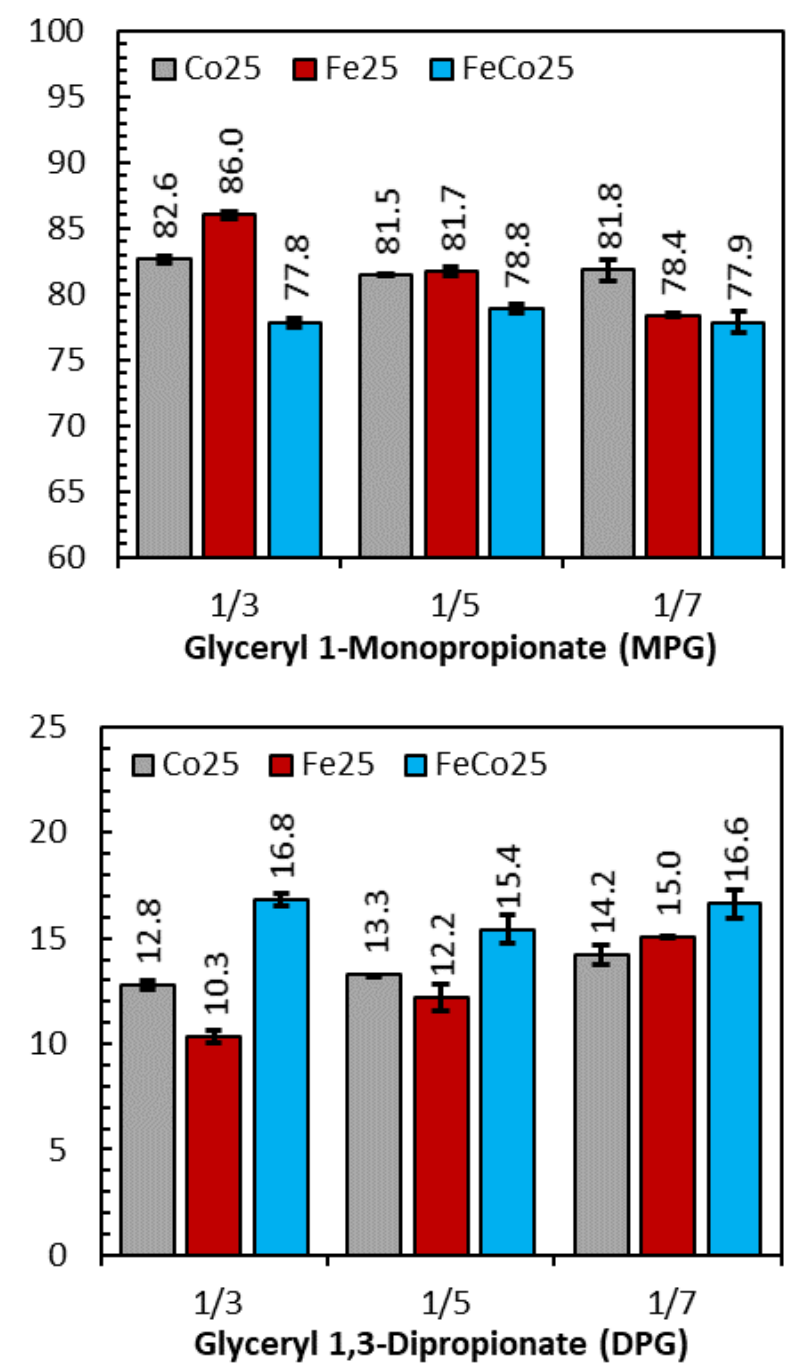

capable of transforming glycerol and forming MPG, DPG, and TPG, important green platform molecules capable to improve renewable energy technologies and new products.

\section{Conclusions}

Synthesis and characterization of Al-MCM41 molecular sieves, impregnated with iron and/or cobalt, was carried out and applied as catalysts in the glycerol acetylation reaction with propionic acid to the product glyceryl mono-, di-, and tri-propionates. XRD analysis identified $\mathrm{Fe}_{2} \mathrm{O}_{3}$ and $\mathrm{Co}_{3} \mathrm{O}_{4}$ oxides with nanometric dimensions and FT-IR showed shift bands by the high presence of aluminum in silicate Al-MCM-41 characteristics and the presence of all structures indicate Lewis and Brønsted acidic sites in the synthesized catalysts. XRF adsorption/desorption $\mathrm{N}_{2}$ isotherms and textural analysis presented MCM- 41 molecular sieves behavior with micropores and mesopores differences according with $\mathrm{Al}$ content in the structure and also $\mathrm{Fe} / \mathrm{Co}$ mass percentage. SEM images showed the presence of spherical small crystallites alternating between well-defined structures until nonuniform clusters. This characteristic view is caused by the high presence of aluminum which increase less defined morphology in MCM-41.

Glycerol acetylation reactions with propionic acid formed mostly glyceryl propionates (mono, di and tri). High yields and selectivity values were obtained in the reactions reaching $79 \%$ yield and $90 \%$ to MPG selectivity in 110 ${ }^{\circ} \mathrm{C}$ condition. Increasing temperature to $130{ }^{\circ} \mathrm{C}$ and the rise of propionic acid concentration

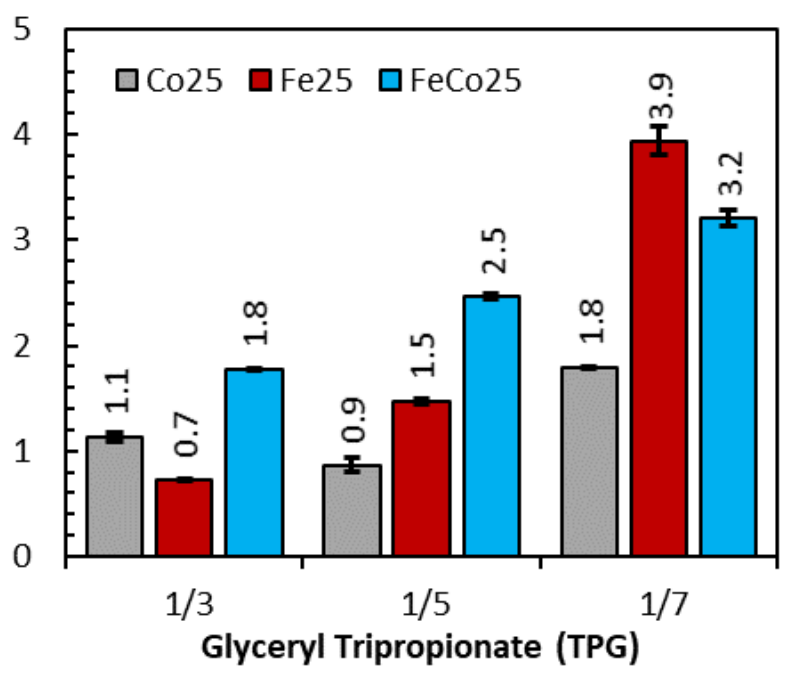

Figure 12. Products selectivity distribution (\%) with varying glycerol/propionic acid ratios and catalysts. 
were favorable to increase the glycerol conversion up to $95 \%$ and maximize selectivity to MPG up to $68 \%$. As the reaction time and temperature advances, the formation of DPG and TPG is observed and, consequently, the decrease of MPG as formed products. In general, catalysts containing iron oxide and a high concentration of aluminum in the chemical structure obtained lower glycerol conversion values, but showed a slightly higher selectivity for DPG and TPG, when compared to catalysts containing cobalt and with lower aluminum content in the structure. The highest reaction yields were obtained with the use of catalysts containing cobalt and iron-cobalt, however more MPG was formed. The acidic materials characteristics associated with the surface area of the pores proved to be determinant for increasing productivity in the formation of glyceryl propionates.

\section{Acknowledgment}

We are grateful to UTFPR - Campus Apucarana, PPGEQ-AP, DEQ-UEM and FACENS. Special thanks to LAMAP-UTFPR and LabmultiLD-UTFPR for supporting this research during the catalyst's characterization analysis. Thanks to CNPq and CAPES for the financial support.

\section{References}

[1] Faria, R.P.V., Pereira, C.S.M., Silva, V.M.T.M., Loureiro, J.M., Rodrigues, A.E. (2013). Glycerol valorisation as biofuels: Selection of a suitable solvent for an innovative process for the synthesis of GEA. Chemical Engineering Journal, 233, 159-167. DOI: 10.1016/j.cej.2013.08.035.

[2] Nakagawa, Y., Tomishige, K. (2011). Heterogeneous catalysis of the glycerol hydrogenolysis. Catalysis Science \& Technology, 1, 179190. DOI: 10.1039/c0cy00054j.

[3] Sudarsanam, P., Mallesham, B., Prasad, A. N., Reddy, P.S., Reddy, B.M. (2013). Synthesis of bio - additive fuels from acetalization of glycerol with benzaldehyde over molybdenum promoted green solid acid catalysts. Fuel Processing Technology, 106, 539-545. DOI: 10.1016/j.fuproc.2012.09.025.

[4] Bagnato, G., Iulianelli, A., Sanna, A., Basile, A. (2017). Glycerol Production and Transformation: A Critical Review with Particular Emphasis on Glycerol Reforming Reaction for Producing Hydrogen in Conventional and Membrane Reactors. Membranes, 7(2), 1-17. DOI: 10.3390/membranes7020017.
[5] Christy, S., Noschese, A., Lomelí-Rodriguez, M., Greeves, N., Lopez-Sanchez, J.A. (2018). Recent progress in the synthesis and applications of glycerol carbonate. Current Opinion in Green and Sustainable Chemistry, 14, 99107. DOI: 10.1016/j.cogsc.2018.09.003.

[6] Katryniok, B., Dumeignil, F. (2013). Recent developments in the field of catalytic dehydration of glycerol to acrolein. ACS Catalysis, 3, 1819-1834. DOI: 10.1021/cs400354p.

[7] Cornejo, A., Barrio, I., Campoy, M., Lázaro, J., Navarrete, B. (2017). Oxygenated fuel additives from glycerol valorization. Main production pathways and effects on fuel properties and engine performance: A critical review. Renewable and Sustainable Energy Reviews, 79, 1400-1413. DOI: 10.1016/j.rser.2017.04.005.

[8] Silva, C.X.A., Gonçalves, V.L.C., Mota, C.J.A. (2009). Water-tolerant zeolite catalyst for the acetalisation of glycerol. Green Chemistry, 11(1), 38-41. DOI: 10.1039/b813564a.

[9] Rahmat, N., Abdullah, A.Z., Mohamed, A.R. (2010). Recent progress on innovative and potential technologies for glycerol transformation into fuel additives: A critical review. Renewable and Sustainable Energy Reviews,

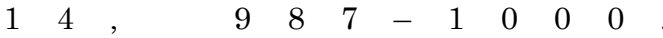
DOI:10.1016/j.rser.2009.11.010.

[10] Pham, T.T., Crossley, S.P., Sooknoi, T., Lobban, L.L., Resasco, D.E., Mallinson, R.G. (2010). Etherification of aldehydes, alcohols and their mixtures on $\mathrm{Pd} / \mathrm{SiO}_{2}$ catalysts. $A p$ plied Catalysis A, General, 379(1-2), 135140. DOI: $10.1016 /$ j.apcata.2010.03.014.

[11] Gu, Y., Azzouzi, A., Pouilloux, Y. (2008). Heterogeneously catalyzed etherification of glycerol: new pathways for transformation of glycerol to more valuable chemicals. Green Chemistry, 10, 164-167. DOI: 10.1039/b715802e.

[12] Silva, C.R.B., Gonçalves, V.L.C., Lachter, E.R., Mota, C.J.A. (2009). Etherification of Glycerol with Benzyl Alcohol Catalyzed by Solid Acids. Journal of the Brazilian Chemical Society, 20(2), 201-204. DOI: 10.1590/S0103-50532009000200002.

[13] Gupta, M., Kumar, N. (2012). Scope and opportunities of using glycerol as an energy source. Renewable and Sustainable Energy Reviews, 16(7), 4551-4556. DOI: 10.1016/j.rser.2012.04.001.

[14] Sun, D., Yamada, Y., Sato, S., Ueda, W. (2016). Glycerol hydrogenolysis into useful C3 chemicals. Applied Catalysis B: Environmental, $193, \quad 75-92$. D O I : 10.1016/j.apcatb.2016.04.013. 
[15] Yamamoto, K., Kiyan, A.M., Bagio, J.C., Rossi, K.A.B., Delabio Berezuk, F., Berezuk, M.E. (2019). Green cyclic acetals production by glycerol etherification reaction with benzaldehyde using cationic acidic resin. Green Processing and Synthesis, 8(1), 183-190. DOI: 10.1515/gps-2018-0059.

[16] Khayoon, M.S., Hameed, B.H. (2011). Acetylation of glycerol to biofuel additives over sulfated activated carbon catalyst. Bioresource Technology, 102(19), 9229-9235. DOI: 10.1016/j.biortech.2011.07.035.

[17] Gonçalves, M., Rodrigues, R., Galhardo, T.S., Carvalho, W.A. (2016). Highly selective acetalization of glycerol with acetone to solketal over acidic carbon-based catalysts from biodiesel waste. Fuel, 181, 46-54. DOI: 10.1016/j.fuel.2016.04.083.

[18] Ekinci, E.K., Oktar, N. (2019). Production of value-added chemicals from esterification of waste glycerol over MCM-41 supported catalysts. Green Processing and Synthesis, 8(1), 128-134. DOI: 10.1515/gps-2018-0034.

[19] De Canck, E., Dosuna-Rodríguez, I., Gaigneaux, E.M., Van Der Voort, P. (2013). Periodic mesoporous organosilica functionalized with sulfonic acid groups as acid catalyst for glycerol acetylation. Materials, 6(8), 35563570. DOI: $10.3390 / \mathrm{ma} 6083556$.

[20] Sánchez, J.A., Hernández, D.L., Moreno, J.A., Mondragón, F., Fernández, J.J. (2011). Alternative carbon based acid catalyst for selective esterification of glycerol to acetylglycerols. Applied Catalysis A: General, 405(1-2), 5560. DOI: 10.1016/j.apcata.2011.07.027.

[21] Gonzalez-Arellano, C., De, S., Luque, R. (2014). Selective glycerol transformations to high value-added products catalysed by aluminosilicate-supported iron oxide nanoparticles. Catalysis Science and Technology, 4(12), 4242-4249. DOI: 10.1039/c4cy00714j.

[22] Khayoon, M.S., Triwahyono, S., Hameed, B.H., Jalil, A.A. (2014). Improved production of fuel oxygenates via glycerol acetylation with acetic acid. Chemical Engineering Journal, $243, \quad 473-484$. D O I : 10.1016/j.cej.2014.01.027.

[23] Gonçalves, C.E., Laier, L.O., Cardoso, A.L., José, M. (2012). Bioadditive synthesis from $\mathrm{H}_{3} \mathrm{PW}_{12} \mathrm{O}_{40}$-catalyzed glycerol esterification with HOAc under mild reaction conditions. Fuel Processing Technology, 102, 46-52. DOI: 10.1016/j.fuproc.2012.04.027.

[24] Wang, L., Liu, Q., Zhou, M., Xiao, G. (2012). Synthesis of glycerin triacetate over molding zirconia-loaded sulfuric acid catalyst. Journal of Natural Gas Chemistry, 21(1), 25-28. DOI: 10.1016/S1003-9953(11)60328-9.
[25] Zhu, S., Zhu, Y., Gao, X., Mo, T., Zhu, Y., Li, Y. (2013). Production of bioadditives from glycerol esterification over zirconia supported heteropolyacids. Bioresource Technology, 130, 45-51. DOI: 10.1016/j.biortech.2012.12.011.

[26] Dhakshinamoorthy, A., Alvaro, M., Garcia, H. (2012). Commercial metal-organic frameworks as heterogeneous catalysts. Chemical Communications, 48(92), 11275-11288. DOI: $10.1039 / \mathrm{c} 2 \mathrm{cc} 34329 \mathrm{k}$.

[27] Zhou, C.H., Beltramini, J.N., Lu, G.Q. (2008). Chemoselective catalytic conversion of glycerol as a biorenewable source to valuable commodity chemicals. Chemical Society Reviews, 37(3), 527-549. DOI: 10.1039/b707343g.

[28] Trifoi, A.R., Agachi, P.Ş., Pap, T. (2016). Glycerol acetals and ketals as possible diesel additives. A review of their synthesis protocols. Renewable and Sustainable Energy Reviews, 62, 804-814. DOI: 10.1016/j.rser.2016.05.013.

[29] Cai, Q., Lin, W.Y., Xiao, F.S., Pang, W.Q., Chen, X.H., Zou, B.S. (1999). The preparation of highly ordered MCM-41 with extremely low surfactant concentration. Microporous and Mesoporous Materials, 32(1-2), 1-15. DOI: $10.1016 / \mathrm{S} 1387-1811(99) 00082-7$.

[30] Corma, A., Fornés, V., Navarro, M.T., PérezPariente, J. (1994). Acidity and stability of MCM-41 crystalline aluminosilicates. Journal of Catalysis, 148(2), 569-574. DOI: 10.1006/jcat.1994.1243.

[31] Heravi, M.M., Hosseini, M., Oskooie, H.A., Baghernejad, B. (2011). Fe/Al-MCM-41: An efficient and reusable catalyst for the synthesis of quinoxaline derivatives. Journal of the Korean Chemical Society, 55(2), 235-239. DOI: $10.5012 / \mathrm{jkcs.2011.55.2.235.}$

[32] Oprescu, E.E., Stepan, E., Dragomir, R.E., Radu, A., Rosca, P. (2013). Synthesis and testing of glycerol ketals as components for diesel fuel. Fuel Processing Technology, 110, 214-217. DOI: 10.1016/j.fuproc.2012.12.017.

[33] Kim, I., Kim, J., Lee, D. (2014). A comparative study on catalytic properties of solid acid catalysts for glycerol acetylation at low temperatures. Applied Catalysis B: Environmental, 148-149, 295-303. DOI: 10.1016/j.apcatb.2013.11.008.

[34] Mallesham, B., Govinda Rao, B., Reddy, B.M. (2016). Production of biofuel additives by esterification and acetalization of bioglycerol. Comptes Rendus Chimie, 19(10), 1194-1202. DOI: 10.1016/j.crci.2015.09.011.

[35] Li, X., Zheng, L., Hou, Z. (2018). Acetalization of glycerol with acetone over $\mathrm{Co}[\mathrm{II}]\left(\mathrm{Co}[\mathrm{III}] \mathrm{xA}_{12-\mathrm{x}}\right) \mathrm{O}_{4}$ derived from layered double hydroxide. Fuel, 233, 565-571. DOI: 10.1016/j.fuel.2018.06.096. 
[36] Zhang, S., Zhao, Z., Ao, Y. (2015). Design of highly efficient $\mathrm{Zn}$-, $\mathrm{Cu}$-, Ni- and Co-promoted M-AlPO ${ }_{4}$ solid acids: The acetalization of glycerol with acetone. Applied Catalysis A: General, $496, \quad 32-39$. D O I : 10.1016/j.apcata.2015.02.006.

[37] Schuette, H.A., Hale, J.T. (1930). Some physical constants of monacetin, monopropin and mono-normal-butyrin. Journal of the American Chemical Society, 52(5), 1978-1981. DOI: 10.1021/ja01368a033.

[38] Gilchrist, P.G., Schuette, H.A. (1931). Monoglycerides of the lower fatty acids. Journal of the American Chemical Society, 53(9), 34803484. DOI: 10.1021/ja01360a038.

[39] Cho, G.H.P., Yeong, S.K., Ooi, T.L., Chuah, C.H. (2006). Glycerol esters from the reaction of glycerol with dicarboxylic acid esters. Journal of Surfactants and Detergents, 9(2), 147152. DOI: 10.1007/s11743-006-0384-9.

[40] Rathod, A.P., Wasewar, K.L., Sonawane, S.S. (2014). Enhancement of esterification of propionic acid with ethanol by pervaporation reactor. Research Journal of Chemistry and Environment, 18(5), 41-44. DOI: $10.1155 / 2014 / 539341$.

[41] Saengarun, C., Petsom, A., Tungasmita, D.N. (2017). Etherification of glycerol with propylene or 1-butene for fuel additives. Scientific World Journal, 2017, 1-11. DOI: $10.1155 / 2017 / 4089036$.

[42] Preethi, E.L., Revathi, S., Sivakumar, T., Manikandan, D., Divakar, D., ValentineRupa, A., Palanichami, M. (2008). Phenol hydroxylation using Fe/Al-MCM-41 catalysts. Catalysis Letters, 120(1-2), 56-64. DOI: 10.1007/s10562-007-9249-8.

[43] Decyk, P., Trejda, M., Ziolek, M., Kujawa, J., Głaszczka, K., Bettahar, M., Monteverdi, S., Mercy, M. (2003). Physicochemical and catalytic properties of iron-doped silica - The effect of preparation and pretreatment methods. Journal of Catalysis, 219(1), 146-155. DOI: 10.1016/S0021-9517(03)00186-6.

[44] Missen, R.W., Mims, C.A., Saville, B.A. (1999). Introduction to Chemical Reaction Engineering and Kinetics, New York, John Wiley \& Sons.

[45] Silva, C., Mota, C.J.A., Pinto, B.P. (2008). Acetylation of glycerol catalyzed by different solid acids. Catalysis Today, 133-135, 673677. DOI: 10.1016/j.cattod.2007.12.037.

[46] Beck, J.S., Vartuli, J.C., Roth, W.J., Leonowicz, M.E., Kresge, C.T., Schmitt, K.D., Chu, C.T.W., Olson, D.H., Sheppard, E.W., McCullen, S.B., Higgins, J.B., Schlenker, J.L. (1992). A New Family of Mesoporous Molecular Sieves Prepared with Liquid Crystal Tem- plates. Journal of the American Chemical Society, 114(27), 10834-10843. DOI: 10.1021/ja00053a020.

[47] Ajaikumar, S., Pandurangan, A. (2008). Reaction of benzaldehyde with various aliphatic glycols in the presence of hydrophobic AlMCM-41: A convenient synthesis of cyclic acetals. Journal of Molecular Catalysis A: Chemical, $290(1-2), \quad 35-43$. D O I : 10.1016/j.molcata.2008.04.008.

[48] Mate, V.R., Shirai, M., Rode, C.V. (2013). Heterogeneous $\mathrm{Co}_{3} \mathrm{O}_{4}$ catalyst for selective oxidation of aqueous veratryl alcohol using molecular oxygen. Catalysis Communications, $33(3), \quad 66-69 . \quad$ D O I : 10.1016/j.catcom.2012.12.015.

[49] Abdelkader, A., Daly, H., Saih, Y., Morgan, K., Mohamed, M.A., Halawy, S.A., Hardacre, C. (2013). Steam reforming of ethanol over $\mathrm{Co}_{3} \mathrm{O}_{4}-\mathrm{Fe}_{2} \mathrm{O}_{3}$ mixed oxides. International Journal of Hydrogen Energy, 38(20), 82638275. DOI: 10.1016/j.ijhydene.2013.04.009.

[50] Alves, I.C.B., Santos, J.R.N., Viégas, D.S.S., Marques, E.P., Lacerda, C.A., Zhang, L., Zhang, J., Marques, A.L.B. (2019). Nanoparticles of $\mathrm{Fe}_{2} \mathrm{O}_{3}$ and $\mathrm{Co}_{3} \mathrm{O}_{4}$ as efficient electrocatalysts for oxygen reduction reaction in acid medium. Journal of the Brazilian Chemical Society, 30(12), 2681-2690. DOI: 10.21577/0103-5053.20190195.

[51] Ertl, G., Knözinger, H., Schülf, F, Weitkamp, J. (1997). Handbook of Heterogeneous Catalysis, Germany, Wiley-VCH.

[52] Fontes, M.S.B., Melo, D.M.A., Costa, C.C., Melo, M.A.F., Alvez, J.A.B.L.R., Silva, M.L.P. (2016). Effect of different silica sources on textural parameters of molecular sieve MCM41. Ceramica, 62, 85-90. DOI: 10.1590/036669132016623611966.

[53] Selvaraj, M., Pandurangan, A., Seshadri, K.S., Sinha, P.K., Lal, K.B. (2003). Synthesis, characterization and catalytic application of MCM-41 mesoporous molecular sieves containing $\mathrm{Zn}$ and $\mathrm{Al}$. Applied Catalysis A: General, $i(2), \quad 347-364$. DOI: 10.1016/S0926860X(02)00527-6.

[54] Camblor, M.A., Corma, A., Pérez-Pariente, J. (1993). Infrared spectroscopic investigation of titanium in zeolites. A new assignment of the $960 \mathrm{~cm}^{-1}$ band. Journal of the Chemical Society, Chemical Communications, 6, 557-559. DOI: 10.1039/C39930000557.

[55] Vidya, K., Gupta, N.M., Selvam, P. (2004). Influence of $\mathrm{pH}$ on the sorption behaviour of uranyl ions in mesoporous MCM-41 and MCM-48 molecular sieves. Materials Research Bulletin, 39(13), 2035-2048. Doi: 10.1016/j.materresbull.2004.07.013. 
[56] Alves, I.C.B., Santos, J.R.N., Viégas, D.S.S., Marques, E.P., Lacerda, C.A., Zhang, L., Zhang, J, Marques, A.L.B. (2019). Nanoparticles of $\mathrm{Fe}_{2} \mathrm{O}_{3}$ and $\mathrm{Co}_{3} \mathrm{O}_{4}$ as efficient electrocatalysts for oxygen reduction reaction in acid medium. Journal of the Brazilian Chemical Society, 30, 2681-2690. DOI: 10.21577/01035053.20190195 .

[57] Sahoo, S., Agarwal, K., Singh, A., Polke, B., Raha, K. (2011). Characterization of g- and a$\mathrm{Fe}_{2} \mathrm{O}_{3}$ nano powders synthesized by emulsion precipitation-calcination route and rheological behaviour of a- $\mathrm{Fe}_{2} \mathrm{O}_{3}$. International Journal of Engineering, Science and Technology, 2(8), 118-126. DOI: 10.4314/ijest.v2i8.63841.

[58] Varghese, S., Cutrufello, M.G., Rombi, E., Cannas, C., Monaci, R., Ferino, I. (2012). CO oxidation and preferential oxidation of $\mathrm{CO}$ in the presence of hydrogen over SBA-15templated $\mathrm{CuO}-\mathrm{Co}_{3} \mathrm{O}_{4}$ catalysts. Applied Catalysis A: General, 443-444, 161-170. DOI: 10.1016/j.apcata.2012.07.038.

[59] Borade, R.B., Clearfield, A. (1995). Synthesis of aluminum rich MCM-41. Catalysis Letters, 31(2-3), 267-272. DOI: 10.1007/BF00808839.

[60] Savidha, R, Pandurangan, A. (2004) Isopropylation of toluene: a comparative study of microporous zeolites and mesoporous MCM-41 materials. Applied Catalysis A: General, 276, 39-50. DOI: 10.1016/j.apcata.2004.04.015.

[61] Carmo Jr, A.C., Souza, L.K.C., Costa, C.E.F., Longo, E., Zamina, J.R., Rocha-Filho, G.N. (2009) Production of biodiesel by esterification of palmitic acid over mesoporous aluminosilicate Al-MCM-41. Fuel, 88, 461-468. DOI: 10.1016/j.fuel.2008.10.007.
[62] Samanta, S., Giri, S., Sastry, P.U., Mal, N.K., Manna, A., Bhaumik, A. (2003). Synthesis and characterization of iron-rich highly ordered mesoporous Fe-MCM-41. Industrial and Engineering Chemistry Research, 42(13), 3012-3018. DOI: 10.1021/ie020905g.

[63] Tran, N.T.T., Uemura, Y., Ramli, A. (2016). Hydrodeoxygenation of Guaiacol over AlMCM-41 Supported Metal Catalysts: A Comparative Study of Co and Ni. Procedia Engineering, $148,1252-1258$. DOI: 10.1016/j.proeng.2016.06.488.

[64] Udayakumar, S., Ajaikumar, S., Pandurangan, A. (2006). Synthesis of commercial important diethyl phthalate over Al-, Fe- and Al, Zn-MCM-41 molecular sieves. Applied Catalysis A: General, 307(2), 245-256. DOI: 10.1016/j.apcata.2006.03.059.

[65] Fletcher, R.E., Ling, S., Slater, B. (2017). Violations of Löwenstein's rule in zeolites. Chemical Science, 8(11), 7483-7491. DOI: 10.1039/c7sc02531a.

[66] Uytterhoeven, J.B., Christner, L.G., Hall, W.K. (1965). Studies of the hydrogen held by solids. VIII. The decationated zeolites. Journal of Physical Chemistry, 69(6), 2117-2126. DOI: $10.1021 / \mathrm{j} 100890 \mathrm{a} 052$.

[67] Pearson, R.G. (1963). Hard and Soft Acids and Bases. Journal of the American Chemical Society, 85(22), 3533-3539. DOI: 10.1021/ja00905a001.

[68] Vasconcellos, M.L.A.A. (2014) A Teoria de Pearson para a disciplina de química orgânica: um exercício prático e teórico aplicado em sala de aula. Química Nova, 37, 171-175. DOI: $10.1590 / \mathrm{S} 0100$ 40422014000100029 . 